\title{
Demografisen kehityksen nykytilanne Pohjoismaissa
}

Fil. maist. KARL-ERIK FORSBERG

Helsingin kaupungin tilastotoimisto

Viimeksi kuluneiden vuosikymmenien aikana eri Pohjoismaissa vallinneet erilaiset olosuhteet ovat merkinneet erilaista lähtökohtaa myös demografiselle kehitykselle. Tässä katsauksessa tarkastellaan tilannetta Suomessa, Ruotsissa, Norjassa ja Tanskassa sekä näitten maitten pääkaupungeissa lähinnä sodanjälkeisenä aikana, joskin aikaisempien vuosien jatkuvaan kehitykseen on myös kiinnitetty huomiota.
Koska väestön rakenne ja väestönmuutokset keskinäisesti vaikuttavat toisiinsa, antaa jo katsaus väestön rakenteeseen usein valaisevan kuvan tietyn yhteisön demografisesta tilasta. Niin on tässäkin syytä aluksi esittää eräitä tietoja nyt kyseessä olevien väestöjen jakautumisista. Seuraavassa asetelmassa on väestö jaettu kolmeen ikäryhmään :

1. Ikäryhmitys, \%

\begin{tabular}{|c|c|c|c|c|c|}
\hline Ikäryhmä & Suomi & Ruotsi & 1956 & Norja & Tanska \\
\hline $0-14$ & 30.6 & 23.7 & & 25.9 & 26.6 \\
\hline $15-64$ & 62.5 & 65.2 & & 63.8 & 63.5 \\
\hline \multirow[t]{2}{*}{65} & 6.9 & 11.1 & & 10.3 & 9.9 \\
\hline & Helsinki & Tukholma & \multirow[t]{4}{*}{1955} & Oslo & Kööpenhamina \\
\hline $0-14$ & 23.4 & 21.0 & & 18.9 & 20.9 \\
\hline $15-64$ & 69.3 & 68.6 & & 70.3 & 68.3 \\
\hline $65-$ & 7.3 & 10.4 & & 10.8 & 10.8 \\
\hline
\end{tabular}

Lapsien osuus koko väestöstä on niin koko Suomessa kuin Helsingissäkin selvästi suurempi kuin muissa maissa, ja vastaavasti on vanhusten osuus pienempi.
Työkykyisessä iässä olevien osuus vaihtelee sangen vähän.

Sukupuolijakautumaa samoissa ikäryhmissä valaisee seuraava asetelma:

2. Naisia 1000 miestä kohden ikäryhmässä

$\begin{array}{lccccc} & 0-14 & \begin{array}{c}15-64 \\ \text { vuotta }\end{array} & 65- & \text { Yhteensä } & \begin{array}{c}\text { Pääkaupunki } \\ (1955)\end{array} \\ \text { Suomi (1957) } & 960 & 1094 & 1684 & 1083 & 1284 \\ \text { Ruotsi } & 946 & 1000 & 1171 & 1005 & 1149 \\ \text { Norja } & 949 & 1000 & 1233 & 1008 & 1170 \\ \text { Tanska (1956) } & 954 & 1026 & 1135 & 1016 & 1157\end{array}$


Ainoastaan lasten ryhmässä on havaittavissa yhtäläisyyttä kaikkiin maihin nähden. Etenkin vanhusten ryhmässä on todettavissa epäsuhtaisuutta Suomessa. Helsinki on myös selvästi naisvoittoisin pää- kaupunki. Muitten maitten ja pääkaupunkien välillä ovat eroavaisuudet pienet.

Vielä esitetään seuraavassa asetelmassa naimattomien osu us tiettyjen ikäryhmien kaikista naisista:

3. Naimattomien naisten osuus koko ikäryhmästä

\begin{tabular}{|c|c|c|c|c|}
\hline Ikäryhmä & Suomi & Ruotsi & Norja & Tanska \\
\hline $\begin{array}{l}15-19 \\
20-24 \\
25-29 \\
30-34 \\
35-39 \\
40-44\end{array}$ & $\begin{array}{l}95.7 \\
59.0 \\
29.0 \\
19.7 \\
17.6 \\
17.8\end{array}$ & $\begin{array}{l}96.2 \\
59.6 \\
26.8 \\
16.5 \\
14.5 \\
15.1\end{array}$ & $\begin{array}{l}96.9 \\
65.7 \\
33.3 \\
20.1 \\
17.3 \\
18.4\end{array}$ & $\begin{array}{l}95.4 \\
51.4 \\
20.1 \\
12.2 \\
11.4 \\
12.6\end{array}$ \\
\hline & $\begin{array}{l}\text { Helsinki } \\
1955\end{array}$ & $\begin{array}{l}\text { Tukholma } \\
1955\end{array}$ & $\begin{array}{l}\text { Oslo } \\
1955\end{array}$ & $\begin{array}{c}\text { Kööpenhamina } \\
1950\end{array}$ \\
\hline $\begin{array}{l}15-19 \\
20-24 \\
25-29 \\
30-34 \\
35-39 \\
40-44\end{array}$ & $\begin{array}{l}96.6 \\
64.8 \\
38.2 \\
25.5 \\
20.5 \\
20.9\end{array}$ & $\begin{array}{l}96.4 \\
60.8 \\
29.0 \\
18.5 \\
15.9 \\
17.1\end{array}$ & $\begin{array}{l}96.5 \\
68.8 \\
35.1 \\
23.0 \\
18.5 \\
18.5\end{array}$ & $\begin{array}{l}95.0 \\
58.3 \\
27.4 \\
16.2 \\
15.0 \\
16.2\end{array}$ \\
\hline
\end{tabular}

Sekä koko Tanskan että Kööpenhaminan sarjat ovat kauttaaltaan alimmat, kun sen sijaan maitten vertailussa Norjan luvut ja pääkaupunkien kohdalla Helsingin luvut ovat yhtä poikkeusta lukuunottamatta korkeimmat. Pääkaupunkien suhdeluvut ovat maitten lukuja korkeampia.

Aviolittoisuusluvut 1000 asukasta kohden ovat tietenkin melko puutteellisia avioliittoisuuden mittoja, koska eri populaatioiden eroavaisuuksia ikäryhmitykseen ja aikaisempiin avioitumissuhteisiin nähden ei ole otettu huomioon. Asetelma 1 osoittaa kuitenkin, että väestön keskiryhmässä $(15-64$ v.) ei ole suuria eroavuuksia eri alueitten välillä. Seuraavassa asetelmassa esitetään eri vuosien avioliittoisuuslukujen aritmeettiset keskiarvot neljän kauden aikana:

4. Solmitut avioliitot 1000 asukasta kohden

$\begin{array}{ccccc}\text { Kausi } & \text { Suomi } & \text { Ruotsi } & \text { Norja } & \text { Tánska } \\ 1935-39 & 8.6 & 8.9 & 8.0 & 9.2 \\ 1940-44 & 8.6 & 9.6 & 8.4 & 9.1 \\ 1945-53 & 9.7 & 8.3 & 8.6 & 9.0 \\ 1954-58 & 7.5 & 7.1 & 7.3 & 7.7 \\ & & & & \\ 1935-39 & \text { Helsinki } & \text { Tukholma } & \text { Oslo } & \text { Kööpenhamina } \\ 1940-44 & 13.1 & 12.9 & 13.4 & 11.7 \\ 1945-53 & 14.7 & 14.0 & 11.6 & 11.4 \\ 1954-58 & 12.7 & 11.4 & 11.4 & 11.2 \\ & 11.2 & 8.8 & 10.1 & 9.5\end{array}$

Maitten välisten lukujen vertailussa panee merkille, että Tanskan luvut kaikkina ajanjaksoina ovat joko ensimmäisellä tai toisella sijalla. Sodan aikana olivat Ruotsin luvut korkeimmat ja sodanjälkeisinä vuosina Suomen. Yli $10 \%$ on todettu yksinomaan Suomessa vuosina 1941 sekä 1945-48. Korkein luku todettiin Suomessa ja Tanskassa 1946, Norjassa 194647 sekä Ruotsissa 1942 ja 1944. Viiden 


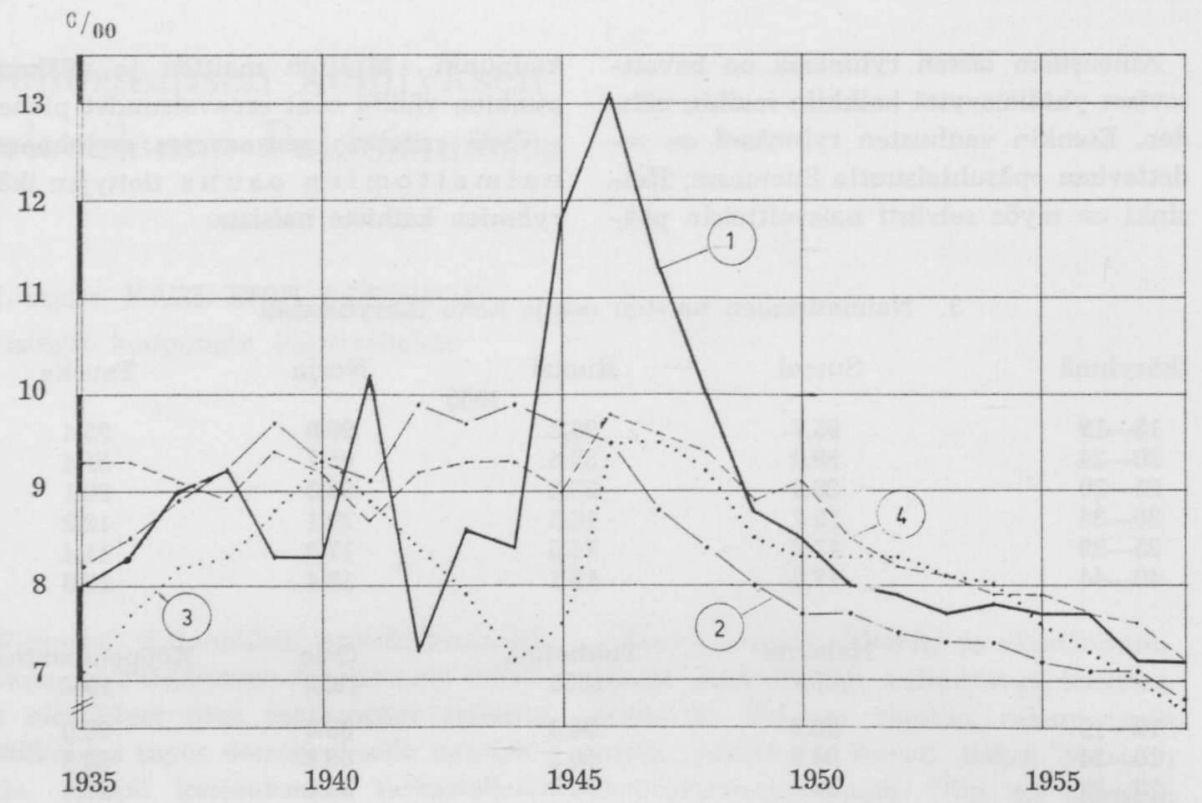

K uvio 1. Avioliittoisuus eli solmittujen avioliittojen määrä 1000 asukasta kohden Suomessa (1), Ruotsissa (2), Norjassa (3) ja Tanskassa (4) vuosina 1935-1958.

viime vuoden aikana ovat eroavuudet olleet hyvin pieniä.

Pääkaupunkien luvut ovat maitten lukuja korkeampia. Osaksi tämä johtuu väestöjen ikäryhmityksestä. Näistä korkeista avioliittoisuusluvuista huolimatta todettiin jo, että naimattomien osuus oli kaupungeissa korkea. Helsingin luvut ovat kauttaaltaan ensimmäisellä tai toisella sijalla, kun taas Kööpenhaminan luvut ovat yleensä olleet alhaisia. Viime viiden vuoden aikanakin on todettava selvä tasoero. Korkein luku todettiin aikaisemmin kuin koko maassa, eli Kööpenhaminassa ja Tukholmassa 1939, Oslossa 1939—40 ja Helsingissä 1941.
Paremman kuvan avioliittoisuudesta pääkaupungeissa saa pohjoismaisten pääkaupunkien tilastollisiin vuosikirjoihin sisältyvästä avioliittoja 1000 naimatonta kohden kuvaavasta taulukosta, mistä ilmenee, että avioliittoikä eri kaupungeissa vaihtelee. Naiset solmivat aikaisin avioliiton Kööpenhaminassa ja myöhään Oslossa ja Tukholmassa. Miesten luvut ovat Helsingissä korkeita sekä alemmissa että ylemmissä ikäryhmissä. Mainitusta taulukosta on alla poimittu iän suhteen standardisoituja indeksilukuja solmituista avioliitoista 1000 naimatonta kohden Kööpenhaminan vuoden 1950 ja 1955 ikäjakautuman mukaisesti:

5. Standardisoidut avioliittoisuusluvut 1000 naimatonta kohden iässä $20-49$ vuotta

\begin{tabular}{|c|c|c|c|c|}
\hline & \multicolumn{2}{|c|}{ Miehet } & \multicolumn{2}{|c|}{ Naiset } \\
\hline & 1950 & 1955 & 1950 & 1955 \\
\hline Helsinki & 163 & 168 & 85 & 97 \\
\hline Tukholma & 136 & - & 118 & \\
\hline Oslo & 120 & 126 & 115 & 108 \\
\hline Kööpenhamina & 163 & 150 & 123 & 110 \\
\hline
\end{tabular}




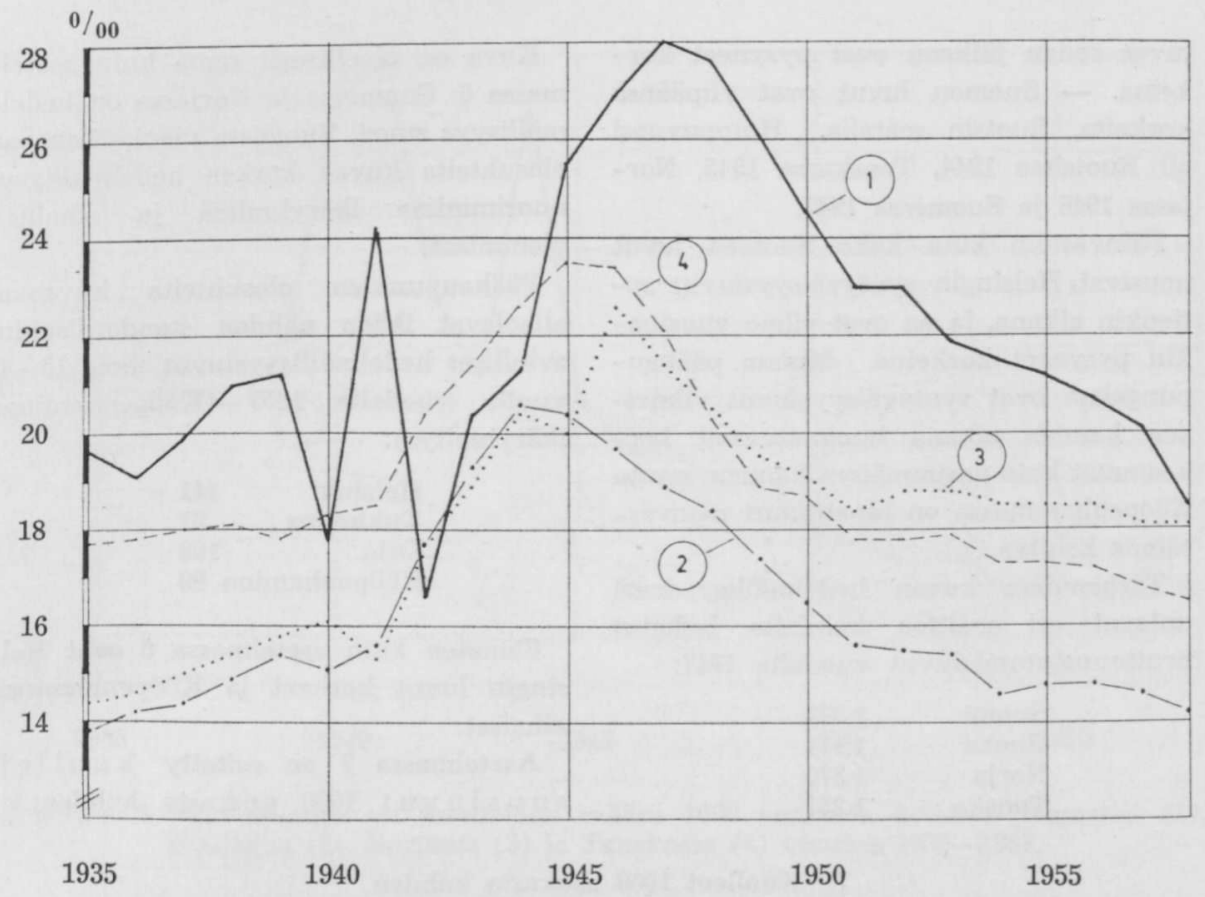

Kuvio 2. Syntyneisyys eli elävänä syntyneiden määrä 1000 asukasta kohden Suomessa (1), Ruotsissa (2), Norjassa (3) ja Tanskassa (4) vuosina 1935-1958.

Helsingin luvut saavat leimansa kaupungin naisvoittoisuudesta. Kööpenhaminan melko korkeat luvut ovat sopusoinnussa siellä todettuun naimattomien naisten pieneen osuuteen.

Syntyväisyyden mittana käyte- tään ensiksi karkeita lukuja, jotka mittaavat elävänä syntyneiden lukua 1000 asukasta kohden. Asetelma 6 antaa yleiskatsauksen kehityksestä neljän kauden aikana:

6. Elävänä syntyneet 1000 asukasta kohden

$\begin{array}{ccccc}\text { Kausi } & \text { Suomi } & \text { Ruotsi } & \text { Norja } & \text { Tanska } \\ 1935-39 & 20.2 & 14.5 & 15.0 & 17.9 \\ 1940-44 & 20.1 & 17.7 & 17.7 & 20.2 \\ 1945-53 & 25.3 & 17.5 & 19.9 & 20.0 \\ 1954-58 & 20.4 & 14.6 & 18.3 & 17.0 \\ & & & & \\ 1935-39 & \text { Helsinki } & \text { Tukholma } & \text { Oslo } & \text { Kööpenhamina } \\ 1940-44 & 12.4 & 11.9 & 10.1 & 15.1 \\ 1945-53 & 18.3 & 18.2 & 12.1 & 18.5 \\ 1954-58 & 20.9 & 17.6 & 14.8 & 16.5 \\ & 17.1 & 14.0 & 13.5 & 12.8\end{array}$

Maitten lukuja tarkastaessa huomaa, että sota-aika merkitsi kohonnutta syntyväisyyttä muualla paitsi Suomessa. Suurten sodanjälkeisten ikäluokkien il- miö on selvimmin tullut näkyviin Suomessa ja Norjassa. Asetelman ensimmäisen ja viimeisen kauden luvut ovat samaa suuruusluokkaa paitsi Norjassa, missä 
luvut sodan jälkeen ovat pysyneet korkeina. - Suomen luvut ovat ylipäänsä korkeita, Ruotsin matalia. Huippuvuosi oli Ruotsissa 1944, Tanskassa 1945, Norjassa 1946 ja Suomessa 1947.

Päinvastoin kuin koko Suomen luvut nousivat Helsingin syntyväisyysluvut sotienkin aikana, ja ne ovat viime vuosinakin pysyneet korkeina. Muissa pääkaupungeissa ovat syntyväisyysluvut viimeisen kauden aikana huomattavasti korkeammat kuin ensimmäisen kauden, mutta Kööpenhaminassa on tapahtunut päinvastainen kehitys.

Tarkemman kuvan hedelmällisyydestä antavat eri maitten kohdalta lasketut bruttouusiutumisluvut vuodelta 1957:

$\begin{array}{ll}\text { Suomi } & 1.375 \\ \text { Ruotsi } & 1.111 \\ \text { Norja } & 1.370 \\ \text { Tanska } & 1.237\end{array}$

Kuva on oleellisesti sama kuin asetelmassa 6: Suomessa ja Norjassa on hedelmällisyys suuri, Ruotsissa pieni. Tanskan olosuhteita kuvaa korkea hedelmällisyys nuorimmissa ikäryhmissä ja alhainen ylemmissä.

Pääkaupunkien olosuhteita kuvaavat allaolevat ikään nähden standardisoidut aviolliset hedelmällisyysluvut iässä 15-44 vuotta vuodelta 1955 (Kööpenhaminan ikäryhmitys):

$\begin{array}{lr}\text { Helsinki } & 141 \\ \text { Tukholma } & 97 \\ \text { Oslo } & 108 \\ \text { Kööpenhamina } & 89\end{array}$

Samaten kuin asetelmassa 6 ovat Helsingin luvut korkeat ja Kööpenhaminan alhaiset.

Asetelmassa 7 on esitetty $\mathrm{kuollei-}$ suusluvut 1000 asukasta kohden:

7. Kuolleet 1000 asukasta kohden

$\begin{array}{ccccc}\text { Kausi } & \text { Suomi } & \text { Ruotsi } & \text { Norja } & \text { Tanska } \\ \text { 1935-39 } & 13.2 & 11.7 & 10.2 & 10.7 \\ 1940-44 & 17.3 & 10.8 & 10.7 & 10.0 \\ 1945-53 & 10.9 & 10.1 & 9.0 & 9.3 \\ 1954-58 & 9.1 & 9.6 & 8.7 & 9.0 \\ & & & & \\ 1935-39 & \text { Helsinki } & \text { Tukholma } & \text { Oslo } & \text { Kööpenhamina } \\ 1940-44 & 11.5 & 11.0 & 10.6 & 11.2 \\ 1945-53 & 16.5 & 10.0 & 10.6 & 10.7 \\ 1954-58 & 10.9 & 9.5 & 9.1 & 10.5 \\ & 9.4 & 9.5 & 9.4 & 10.7\end{array}$

Silmiin pistävää on ennen kaikkea Suomen ja Helsingin korkeat sodanaikaiset kuolleisuusluvut, kun taas muualla sotakaudenkin aikana on todettavissa aleneva tai muuttumaton kuolleisuus. Suomen luvut poikkeavat muitten maitten luvuista myös ensimmäisen kauden aikana, mutta viime kauden luvut osoittavat enää ainoastaan pieniä eroavaisuuksia. Kööpenhaminan luvut ovat mainittuna kautena muitten pääkaupunkien lukuja korkeampia.

$$
\begin{gathered}
\text { Kuolleisuus v. } 1956 \text { ikäryhmässä } \\
40-44 \text { vuotta } \\
1000 \text { asukasta kohden }
\end{gathered}
$$

$\begin{array}{lcc} & \text { Miehet } & \text { Naiset } \\ \text { Suomi } & 6.5 & 3.1 \\ \text { Ruotsi } & 2.8 & 1.9 \\ \text { Norja } & 2.5 & 1.6 \\ \text { Tanska } & 2.6 & 2.2\end{array}$

Esitetyt luvut antavat tietenkin oikean kuvan kuolleisuuden suhteesta koko väkilukuun. Sen sijaan ne ovat harhaanjohtavia, jos haluaa nimenomaan verrata kuolleisuutta eri tutkituilla alueilla, mikä johtuu siitä ikäryhmitysten eroavaisuudesta, joka ilmeni asetelmassa 1.

Tätä osoittaa selvästi muutama lukusarja tilastollisten vuosikirjojen kansainvälisistä vertailutaulukoista:
Jäljellä oleva keskimääräinen elinaika 0 vuoden iässä 1951-55

$\begin{array}{cc}\text { Miehet } & \text { Naiset } \\ 63.4 & 69.8 \\ 70.5 & 73.4 \\ 71.1 & 74.7 \\ 69.9 & 72.6\end{array}$




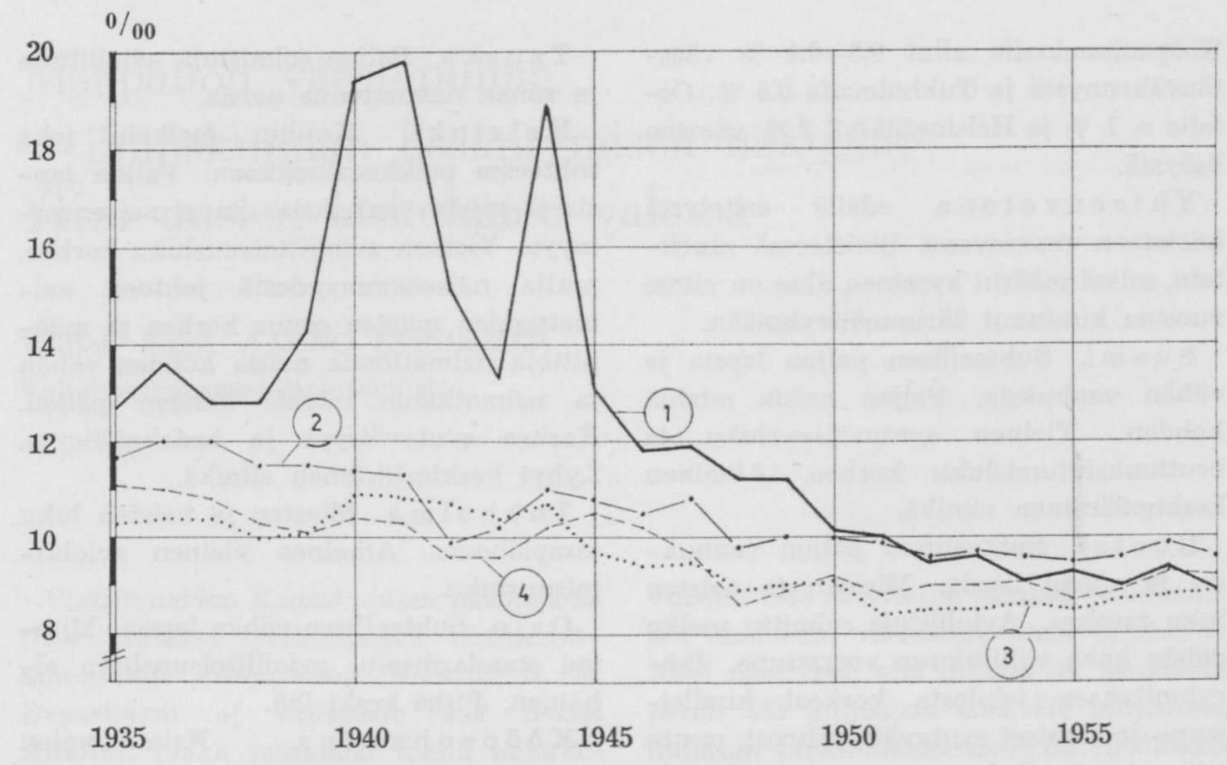

Kuvio 3. Kuolleisuus eli kuolleiden määrä 1000 asukasta kohden Suomessa (1), Ruotsissa (2), Norjassa (3) ja Tanskassa (4) vuosina 1935-1958.

Edullisimmat ovat Norjan olot ja toisella sijalla tulee elinaikaan nähden Ruotsi. Myös Tanskan luvut ovat samaa suuruusluokkaa. Suomen luvut ovat sitä vastoin aivan toista luokkaa. Huomattavaa on lisäksi, että Suomessa naisten keskimääräinen elinaika on yli 6 vuotta pitempi kuin miesten, kun se muualla ylittää miesten ainoastaan n. 3 vuodella. Pääkaupunkien kohdalta on vuodelta 1955 laskettu seuraavat ikään nähden standardisoidut kuolleisuusluvut:

$\begin{array}{lcc} & \text { Miehet } & \text { Naiset } \\ \text { Helsinki } & 16.1 & 11.0 \\ \text { Tukholma } & 10.9 & 9.1 \\ \text { Oslo } & 9.8 & 8.4 \\ \text { Kööpenhamina } & 11.1 & 9.6\end{array}$

Edullismmat ovat Oslon luvut. Naisten kohdalta Helsingin luvut eivät paljon eroa muitten pääkaupunkien luvuista, mutta miesten luku on paljon korkeampi.

Syytä tähän olotilaan hakiessa joutuu kiinnittämään huomiota kuolemansyytietoihin. Jo karkeat luvut osoittavat, että tuberkuloosi edelleen vaatii uhreja Suomessa enemmän kuin muualla. Tarkempi tutkimus, missä kuolemansyitä on tarkas- teltu ikäryhmittäin ja joka vuonna 1956 on julkaistu julkaisussa Tilastollisia kuukausitietoja Helsingistä, osoittaa, että melkein kaikissa ikä- ja kuolemansyyryhmissä luvut ovat epäedullisempia Suomessa kuin Ruotsissa ja Helsingissä kuin Tukholmassa.

Muttoliike merkitsee hyvin vähän maitten väestön kehitykseen. Muilla mailla on pieni siirtolaistappio, Ruotsilla pieni voitto. Tärkeämpi osa on muuttoliikkeellä ollut pääkaupunkien kehityksessä. Nyttemmin on kuitenkin Kööpenhamina täyteen rakennettu, mistä on seurauksena hallinnollisen pääkaupunkialueen muuttotappio, ja myös Tukholmassa on muuttovoitto tästä syystä huomattavasti alentunut. Osloon ja Helsinkiin on 1940-luvulla liitetty suuret alueet, joten on edellytyksiä näitten kaupunkien kasvamiseen. Muuttovoitto merkitsi vuonna 1958 Oslossa 0.5 ja Helsingissä 1.3 $\%$ :n väestönlisäystä.

Eri väestönmuutostekijäin johdosta on väestö viime vuosina lisääntynyt kaikissa maissa, eniten Suomessa ja Norjassa, missä lisäys on ollut vajaa $1 \%$. Ruotsissa ja Tanskassa on vastaava luku ollut $0.7-0.5 \%$. - Pääkaupungeista on 
Kööpenhaminalla ollut $0.8-0.4 \%$ väestönvähennystä ja Tukholmalla $0.6 \%$, Oslolla n. $1 \%$ ja Helsingillä yli $2 \%$ väestön lisäystä.

Yhteenvetona edellä esitetystä toistetaan seuraavassa tiivisteessä alueittain, missä määrin kyseinen alue on viime vuosina kuulunut äärimmäisryhmään.

Su omi. Suhteellisen paljon lapsia ja vähän vanhuksia. Paljon naisia miehiä kohden. Yleinen syntyväisyysluku ja bruttouusiutumisluku korkea. Alhainen keskimääräinen elinikä.

Ruotsi. Suhteellisen paljon vanhuksia ja vähän lapsia. Miesten ja naisten luku tasoissa. Avioliittoja solmittu melko vähän koko väkilukuun verrattuna. Ikäryhmityksen johdosta korkeat kuolleisuus- ja alhaiset syntyväisyysluvut, mutta sitä paitsi myös bruttouusiutumisluku alhainen.

$\mathrm{N}$ orja. Paljon naimattomia naisia. Alhainen yleinen kuolleisuusluku ja pitkä keskimääräinen elinikä.
T a n ska. Paljon solmittuja avioliittoja ja vähän naimattomia naisia.

Helsinki. Kuuluu melkein joka suhteessa poikkeusluokkaan. Paljon lapsia ja vähän vanhuksia. Suuri naisenemmyys. Yleinen avioliittoisuusluku korkea, mutta naisenemmyydestä johtuen naimattomien naisten osuus korkea ja avioliittoja naimattomia naisia kohden vähän ja naimattomia miehiä kohden paljon. Korkea syntyväisyys ja hedelmällisyys. Lyhyt keskimääräinen elinikä.

Tukholma. Miesten ja naisten luku tasapainossa. Alhainen yleinen avioliittoisuusluku.

Os 1 o. Suhteellisen vähän lapsia. Miesten standardisoitu avioliittoisuusluku alhainen. Pitkä keski-ikä.

Kööpenhamina. Naimattomien naisten osuus pieni ja naisten standardisoitu avioliittoisuusluku korkea. Syntyväisyys ja hedelmälliysys alhainen. Yleinen kuolleisuusluku suhteellisen korkea. 